\title{
FORMULATION AND PHYSICOCHEMICAL CHARACTERIZATION OF PIROXICAM CONTAINING POLYMER FILMS
}

\author{
Sayed H. Auda*, Mahmoud M. Ahmed, S. Abd El-Rasoul and K. I. Saleh \\ Department of Pharmaceutics and Industrial Pharmacy, Faculty of Pharmacy, Al-Azhar \\ University, Assiut branch, Assiut, Egypt
}

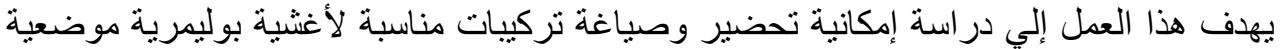

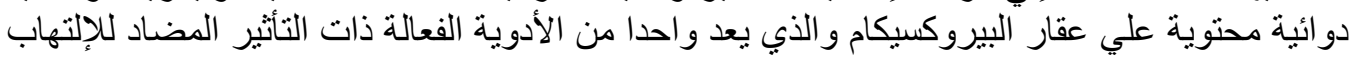

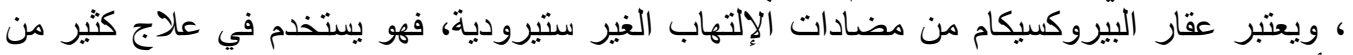

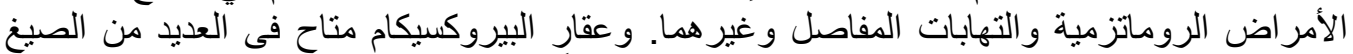

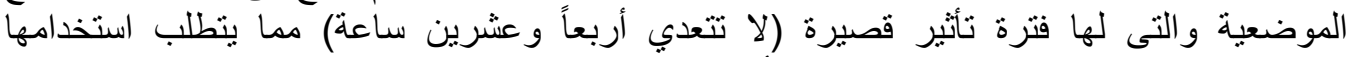

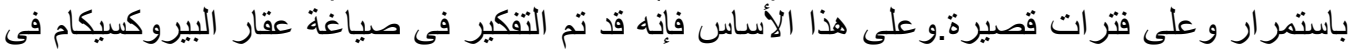

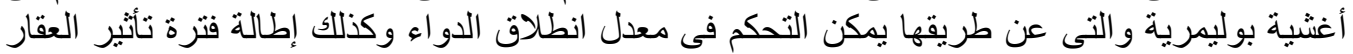

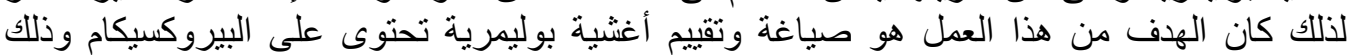

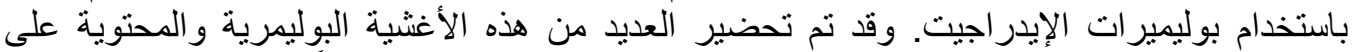

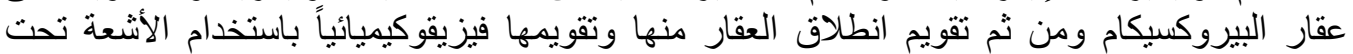
الحمر اء و المسح الحر اريكام ودي وحيود الأشعة السينية.

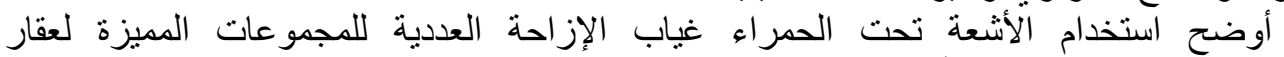

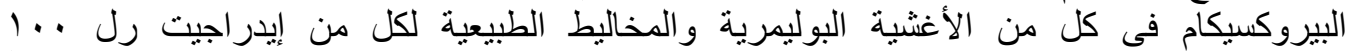

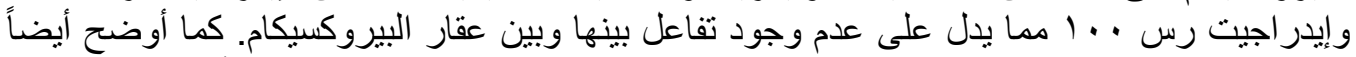

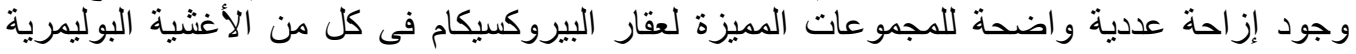

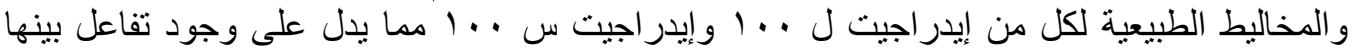

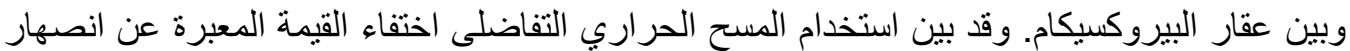

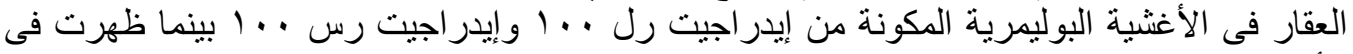

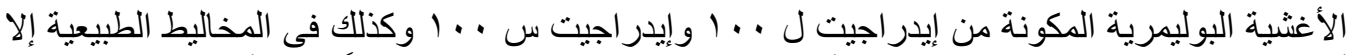

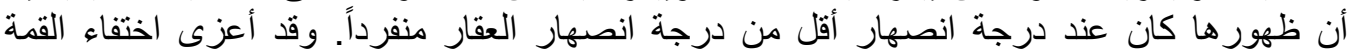

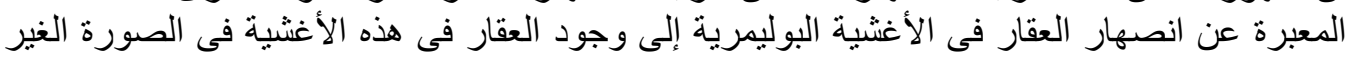

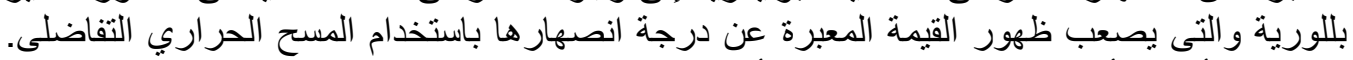

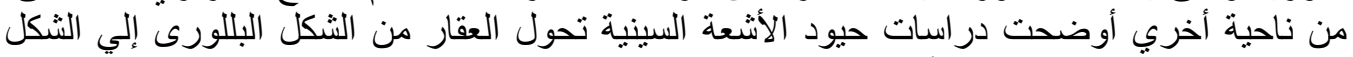

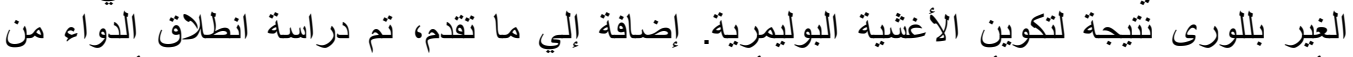

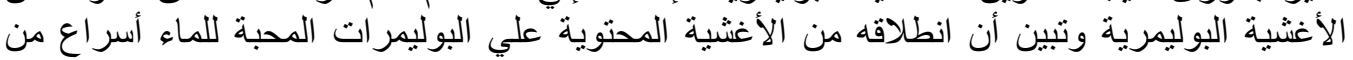
انطلاقه من تللك المحتوية علي البوليمر ات الكار هة للماء.
\end{abstract}

Piroxicam is a potent nonsteroidal anti-inflammatory drug associated with many side effects when taken orally. An attention was paid in this work to formulate and characterize piroxicam containing polymer films for dermal use. The used polymers were Eudragit types namely Eudragit RL100, RS100, L100 and Eudragit S100. In this study, medicated films consisting of drug and carrier were prepared. The carrier consisted of one or two polymers. The physicochemical characterization was done by IR spectroscopy, DSC and X-Ray diffractometry for both piroxicam polymeric films and their corresponding physical mixtures as well as the untreated drug and polymer powders to investigate the drug polymer interaction. The results indicate presence of molecular interactions between piroxicam and both Eudragit L100 and Eudragit S100 and no interactions were found between piroxicam and Eudragit RL100 or Eudragit RS100. In-vitro drug release from Eudragit films was studied. It is found that the drug release from hydrophilic polymers is faster than that from hydrophobic ones. 


\section{INTRODUCTION}

Piroxicam, an oxime derivative, is a nonsteroidal anti-inflammatory drug. It is used in musculoskeletal and joint disorders such as ankylosing spondylitis, osteoarthritis, rheumatoid arthritis including juvenile chronic arthritis, in soft- tissue disorder, and in acute gout ${ }^{1}$. The drug is highly potent, has a long half-life of over $50 \mathrm{hrs}$ which makes it suitable for once daily dosage ${ }^{2}$.

Piroxicam exists in two different interconvertible crystal polymorphs with melting points of $196-198^{\circ} \mathrm{C}$ for the needle form and $199-201{ }^{\circ} \mathrm{C}$ for the cubic form and there are no data about a possible different activity of the particular forms ${ }^{3}$. There are two possible tautomeric forms for piroxicam, namely enol and ketone forms ${ }^{4}$. The chemical structure of piroxicam in its enol and ketone forms is shown below.

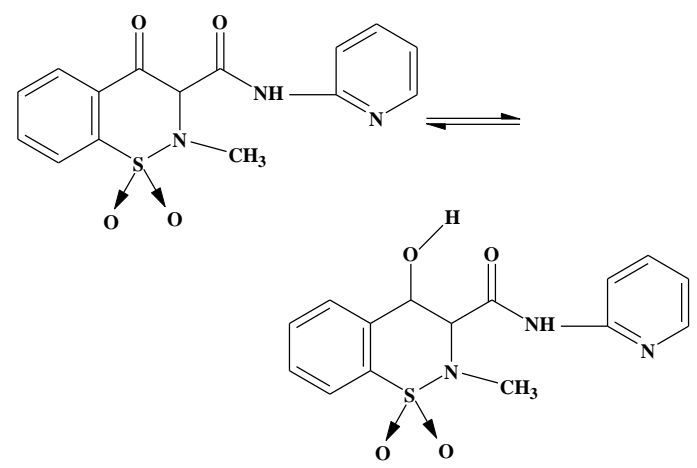

The chemical structure of piroxicam in its enol and ketone forms.

Application of medicated substances to the skin is a concept as old as humanity. For treatment of skin infections, wide assortments of topical dosage forms are available. It comprises powders, lotions, emulsions, ointments, pastes, aerosols, soaps, plasters, shampoos and other preparations. Today, among these preparations, ointment - like preparations, covers about $80 \%$.

The application of some ointments to the skin produces systemic actions, which means, certain degree of absorption occurs. Afterwards, systemic drug administration by the transdermal route was achieved with some cream and ointment preparations for protection and treatment from certain diseases. None of these preparations was satisfactory; the major disadvantage was variable systemic drug absorption due to the absence of specific directions as to the area to be covered as well as the duration of systemic action was controlled by the thickness of the layer of ointment or cream, which varies with repeated application by patient.

For such reasons medicated topical polymeric films are designed to deliver the drug to the skin surface at a controlled rate. The main advantages of such solid dosage forms ${ }^{5}$ are:- 1) Elimination of variables, which influence G. I. T absorption, 2) Avoidance of first pass effect, 3) Allows administration of drug with small therapeutic index, 4) Permits display of only one pharmacological effect from a drug that in another dosage form may show several effects, 5) An alternative route when oral route is not practicable, 6) Elimination of nuisance associated with daily repetitive applications of messy ointments and creams (patient compliance is better), 7) Flexibility of the dose used, it has a definite area. (i.e increase area leads to increase in dose and 8) Easy to terminate therapy by removing the system. These advantages confirm that drug-containing polymer films are very promising medicinal preparations.

The aim of this paper is formulation and Physicochemical characterization of a dermatological preparation as a film for common drug used widely but associated with many side effects when taken orally, namely piroxicam, which belongs to non-steroidal anti - inflammatory drugs. Such film could be applied conveniently to the skin, releasing the drug in an effective concentration; so that continuous effect would be achieved for a reasonable time ${ }^{5}$.

In this study, medicated films consisting of drug and carrier were prepared. The carrier consisted of one or two polymers. The physicochemical characterization was done by IR spectroscopy, DSC and X-Ray diffractometry for piroxicam polymeric films and the corresponding physical mixtures as well as the untreated drug and polymer powders to investigate the drug polymer interaction. In-vitro release of the drug from Eudragit films was also studied. 


\section{EXPERIMENTAL}

\section{Materials and methods \\ Materials}

Piroxicam (kindly provided by Sedico company for pharmaceutical industries, Cairo, Egypt). Eudragit RS100, Eudragit RL100, Eudragit S100 and Eudragit L100 (Roehm pharma, GMBH, Darmstadt, W. Germany). Acetone (El-Nasr company, Abu-Zaabal, Cairo, Egypt).

\section{Preparation of Eudragit films}

Specified weights of Eudragit polymer and piroxicam $(20 \mathrm{mg}$ of piroxicam and $480 \mathrm{mg}$ of polymer, 2:50) were gradually transferred to a $100 \mathrm{ml}$ beaker containing $20 \mathrm{ml}$ of the casting solvent (acetone); the beaker was covered with aluminum foil paper to prevent solvent evaporation. The casting solution was subjected to gentle stirring for 2 hrs. The casting solution $(25 \mathrm{ml})$ was transferred into a previously cleaned and dried teflon coated plate. The Teflon plate $\left(\right.$ area $=22.26 \mathrm{~cm}^{2}$ ) was covered with an inverted glass funnel of stem orifice $0.6 \mathrm{~cm}$ in diameter. The funnel was an aid to ensure slow and uniform evaporation of the solvent and to prevent blistering of the film. This also ensured uniform distribution of drug particles in the film. The solvent was allowed to evaporate for $72 \mathrm{hrs}$; the film was then removed from the Teflon plate and was allowed to dry in desiccator at least $48 \mathrm{hrs}$ before evaluation. The films were wrapped in an aluminum foil and stored in a dry place at ambient room temperature the films were subjected to evaluation within one week of their preparation.

\section{Physicochemical characterization}

IR spectra of certain medicated films and the corresponding physical mixtures as well as the untreated drug were done at a range of $4000-400 \mathrm{~cm}^{-1}$ using $\mathrm{KBr}$ disk method. The samples were ground, mixed thoroughly with $\mathrm{KBr}$ and compressed at a pressure of 6 ton $/ \mathrm{cm}^{2}$ using Shimadzu SSp-10A IR compression machine. Differential scanning calorimetry was recorded using T.A. 501 Differential scanning calorimeter DSC. (Shimadzu Co., Japan). Samples of about $5 \mathrm{mg}$ were accurately weighed and encapsulated into flat-bottomed aluminum pans with crimped-on lids. The scanning speed of $10^{\circ} \mathrm{C} / \mathrm{min}$ from $0^{\circ} \mathrm{C}$ to $250^{\circ} \mathrm{C}$ was used in presence of nitrogen at flow rate of $40 \mathrm{ml} / \mathrm{min}$. The X-ray diffraction patterns of the powder samples were obtained using a Phillips 1700 series diffractometer which is equipped with curved graphite crystal monochromater, automatic divergence slit and automatic controller PW/1710. The target used was $\mathrm{CuK} \alpha$ radiation operating at $40 \mathrm{KV}$ and 30 $\mathrm{mA}(\lambda \mathrm{ka}=1.5418 \mathrm{~A})$. The system was calibrated using silicon disc and/or powder $\mathrm{d} 111=3.1355 \mathrm{~A}$ ) as an external standard. The diffraction patterns were achieved using continuous scan mode with $20^{\circ}$ ranging from $4^{\circ}$ to $60^{\circ}$. The output data achieved represented by $20, \mathrm{~d} \mathrm{~A}$, intensities are determined via the microprocessor of the PW/1710.

\section{In-vitro drug release experiments}

The previously prepared film was removed from the plate, weighed on an analytical balance, and the thickness was measured at both the four corners and the center with a micrometer. A thin coating of silicone adhesive was applied to back of petri dish (7 $\mathrm{cm}$ in diameter) which was used as a glass support. The film was carefully pressed on to the glass support, making sure that all edges are adhered and no silicon adhesive touched the exposed surface.

The temperature of the dissolution medium $(250 \mathrm{ml})$ of citrate buffer $(\mathrm{pH}=5)$ was adjusted to $32+0.5^{\circ} \mathrm{C}$. Even though, the body temperature is maintained at $37+0.5^{\circ} \mathrm{C}$, the temperature of the skin surface is $32+0.5^{\circ} \mathrm{C}$. Therefore, the temperature of release studies was maintained at $32^{\circ} \mathrm{C}$ rather than at $37^{\circ} \mathrm{C}$. The $\mathrm{pH}$ of the intact skin lies between 4.5 to 5.5 under occlusive condition, the $\mathrm{pH}$ of the skin is more likely to be close to the higher value rather than to the lower value. Condition of release studies at $(\mathrm{pH}=5)$ simulates the condition upon which the drug is exposed when applied to the intact skin. The glass support containing the film was placed in the bottom of the vessel, then the paddles of the dissolution tester were allowed to rotate at $60 \mathrm{rpm}$ which was the optimum speed to prevent film rupture. It was taken into consideration that the used buffer volume affords sink conditions. To avoid water evaporation, the vessels were covered with an aluminum foil during the experiments. 
Samples (5 ml each) were obtained while the film remained completely immersed throughout the release study. The removed sample $(5 \mathrm{ml})$ from the release medium was replaced by an equal volume of buffer. The run was continued for at least $6 \mathrm{hrs}$. All samples were analyzed spectrophotometrically at 360 $\mathrm{nm}$. Blank samples were obtained from the release experiments films containing the same components except the drug.

\section{RESULTS AND DISCUSSION}

\section{IR spectroscopy}

There are two possible tautomeric forms for piroxicam, but in this study the $1724 \mathrm{~cm}^{-1}$ band was not observed in the IR spectrum of piroxicam, suggesting that piroxicam was present as an enol form ${ }^{4}$. It has also been reported that piroxicam has two interconvertible crystalline forms, namely the needle and cubic forms ${ }^{1}$. The IR absorption peaks at $1634 \mathrm{~cm}^{-1}$ and $1629 \mathrm{~cm}^{-1}$ are assigned to the stretching of the amide carbonyl groups of the needle form and the cubic form of piroxicam respectively, the peak at $1529 \mathrm{~cm}^{-1}$ is due to the stretching of the second amide band for both crystalline forms of piroxicam. The peak at $1629 \mathrm{~cm}^{-1}$ was found in the IR spectrum of piroxicam, suggesting that the cubic form of piroxicam was used in the present study.

The IR spectra (Figs. 1,2) indicate absence of changes in the location or width of the characteristic infrared absorption bands of the drug in either the case of physical mixtures or cast films of piroxicam: Eudragit RL100 and/or Eudragit RS100 suggesting that there is no interaction between piroxicam: Eudragit RL100 and Eudragit RS100. No crystalline transformation of piroxicam induced by Eudragit RL100 and Eudragit RS100 was observed after evaporation of acetone. Similar results were obtained by some researchers ${ }^{6}$ who studied piroxicam polymer interaction using Eudragit E, Eudragit RL100 and Eudragit S100.

Adibkia et $\mathrm{al}^{7}$ investigated the physicochemical characterizations of nanoparticles of piroxicam and eudragit RS. They found that there is no chemical interaction between them.

However, the IR spectra of powder of piroxicam : Eudragit L100 : Eudragit S100 (Fig. 3) shows several new peaks at 1640 and at
$1525 \mathrm{~cm}^{-1}$ in the physical mixture were shifted from 1629 and $1529 \mathrm{~cm}^{-1}$ respectively. This change was due to the carbonyl stretching peak at $1629 \mathrm{~cm}^{-1}$ which is previously formed due to the intermolecular hydrogen bonding with the hydroxyl group of the polymers.

In the case of the cast films (Fig. 4) of piroxicam : Eudragit L100 and Eudragit S100, drug polymer interaction was observed after solvent evaporation, and the peak at $1629 \mathrm{~cm}^{-1}$ was shifted to the lower wave number of 1661 $\mathrm{cm}^{-1}$ in case of piroxicam : Eudragit L100 films (2:50 weight ratio), $1650 \mathrm{~cm}^{-1}$ in case of piroxicam : Eudragit S100 films (2:50 weight ratio) and $1648 \mathrm{~cm}^{-1}$ in piroxicam : Eudragit L100 : Eudragit S100 films (2:25:25 weight ratio). This change may be attributed to the difference between the two polymers in the hydroxyl group ratios that gives different possibility in the hydrogen bonding formation.

Moreover, the peak at $1529 \mathrm{~cm}^{-1}$ assigned to the second amide band of piroxicam was shifted to $1521 \mathrm{~cm}^{-1}$ due to the intermolecular interaction between piroxicam and both Eudragit L100 and Eudragit S100. Bands at $1634 \mathrm{~cm}^{-1}$ and $1530 \mathrm{~cm}^{-1}$ corresponding to the needle form of piroxicam were observed in the IR spectra of piroxicam: Eudragit L100 and Eudragit S100 films (polymorphism phenomenon). This indicates that both Eudragit L100 and Eudragit S100 can interact with piroxicam on the solid state of the physical mixture and on the solid state of films after evaporation of the solvent and can induce the transformation of piroxicam from cubic to needle form.

Similar results were obtained by Maghsoodi and Sadeghpoor. They studied the FTIR spectra of solid dispersion of piroxicam and Eudragit S100. They attributed the shift of spectra to presence of a solid-state hydrogenbonding interaction between amorphous piroxicam and Eudragit S100 in the prepared microparticles $^{8}$. Furthermore, others ${ }^{9}$ noticed that both $\mathrm{N}-\mathrm{H}$ and $\mathrm{O}-\mathrm{H}$ stretching bands of piroxicam were shifted toward lower wave number in case of solid dispersion with polyvinyl pyrolydone. They attributed this observation to the presence of the intermolecular hydrogen bonding between $\mathrm{N}-\mathrm{H}$ and $\mathrm{O}-\mathrm{H}$ stretching of piroxicam and $\mathrm{C}=\mathrm{O}$ of polyvinyl pyrolydone during the dispersion process. 


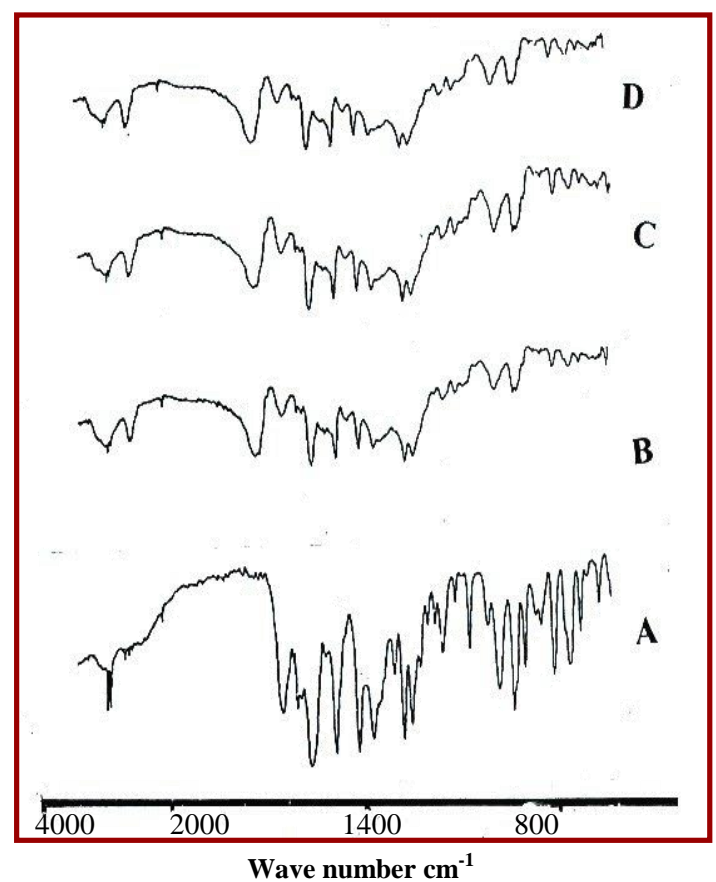

Fig. 1: The IR spectra of (A) Untreated piroxicam powder, (B) Eudragit RL 100, (C) Eudragit RS 100 and (D) Piroxicam : Eudragit RL100:Eudragit RS100 (2:50:50) physical mixture.

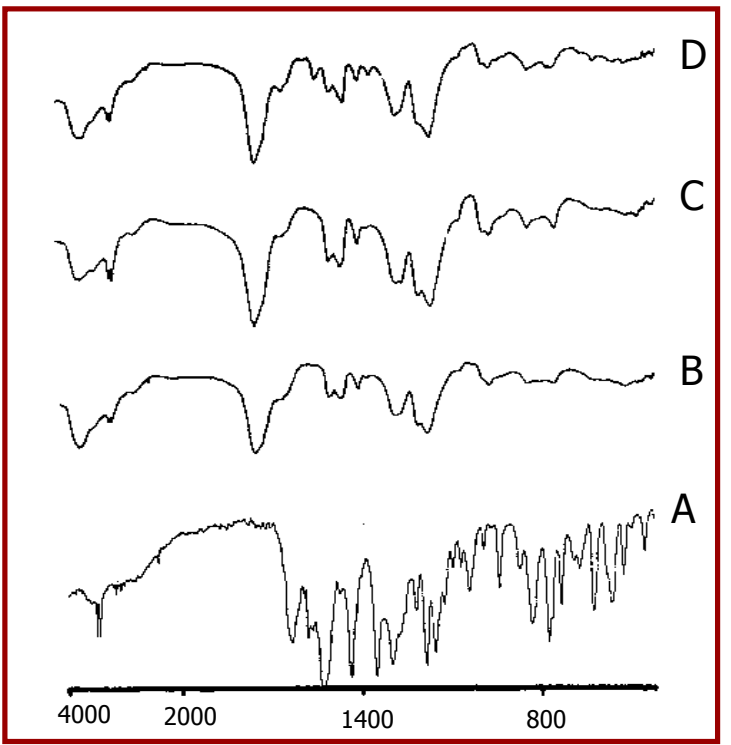

Wave number $\mathrm{cm}^{-1}$

Fig. 3: The IR spectra of (A)Untreated piroxicam powder, (B) Eudragit L 100, (C) Eudragit S 100 and (D) Piroxicam : Eudragit L100 : Eudragit S100, (2:25:25 w/w) physical mixture.

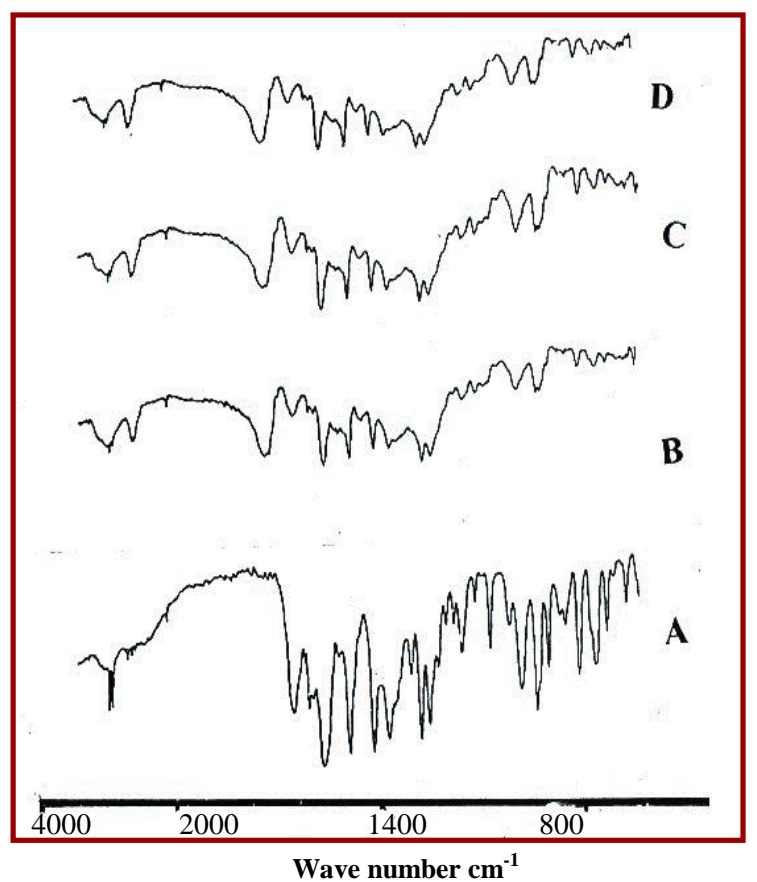

Fig. 2: The IR spectra of (A) Untreated piroxicam powder, (B) piroxicam : Eudragit RL100 $(2: 50 \mathrm{w} / \mathrm{w})$ film, (C) piroxicam : Eudragit RS100 (2:50 w/w) film and (D) Piroxicam : Eudragit RL100:Eudragit RS100 (2:50:50) film.

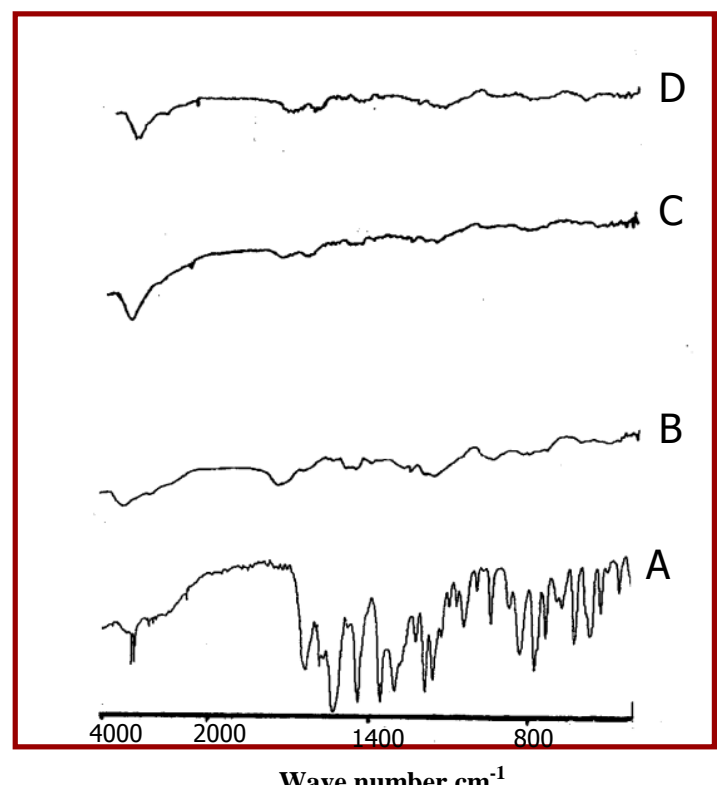

Fig. 4: The IR spectra of (A) Untreated piroxicam powder, (B) piroxicam : Eudragit L100 (2:50 w/w) film, (C) piroxicam:Eudragit S100 (2:5 w/w) film and (D) Piroxicam : Eudragit L100:Eudragit S100 (2:25:25 w/w) film. 


\section{Differential scanning calorimetery (DSC)}

In order to shed a light on the possibility of solid state changes of piroxicam with different used polymers, DSC was performed on drug: polymer cast films (2:50 weight ratio of drug: polymer) and their physical mixtures as well as the individual components.

The DSC curves of untreated piroxicam show an endothermic peak at $201.3^{\circ} \mathrm{C}$ at a scanning rate of $10^{\circ} \mathrm{C} / \mathrm{min}$. No melting endothermic peaks of piroxicam crystal were observed in either the physical mixtures or cast films of piroxicam: Eudragit RL100 (2:50 w/w), piroxicam: Eudragit RS100 (2:50 w/w) or piroxicam: Eudragit RS100 and Eudragit RL100 (2:25:25 w/w) (Figs. 5,6). This observation indicates the presence of piroxicam in an amorphous form in these two cases.

DSC thermogram of piroxicam : Eudragit S100 : Eudragit L100 (2:25:25 w/w) physical mixture (Fig. 7) shows that the endothermic peak of the drug exists at lowered position compared to the untreated drug and lost its distinct sharpened appearance. This observation suggests presence of an interaction between piroxicam and these two polymers. The interaction between piroxicam and Eudragit S100 was confirmed by Maghsoodi and Sadeghpoor. They investigated the DSC of solid dispersion of piroxicam and Eudragit $\mathrm{S} 100^{8}$.

Piroxicam exhibited polymorphism phenomenon in the cast films of both piroxicam : Eudragit L100 (2:50 w/w), piroxicam : Eudragit S100 (2:50 w/w) and piroxicam : Eudragit S100 : Eudragit L100 $(1: 25: 25 \mathrm{w} / \mathrm{w})$ (Fig. 8). The presence of polymorphism can be seen by the existence of two endotherms in the thermogram (at $175.2^{\circ} \mathrm{C}$ and $190.1^{\circ} \mathrm{C}$ ) with Eudragit L100 films, (at $159.3^{\circ} \mathrm{C}$ and $185.7^{\circ} \mathrm{C}$ ) with Eudragit $\mathrm{S} 100$ films and (at $170.2^{\circ} \mathrm{C}$ and $193.9^{\circ} \mathrm{C}$ ) with piroxicam : Eudragit L100 : Eudragit S100 $(2: 25: 25 \mathrm{w} / \mathrm{w})$ films. These DSC results confirmed the previous IR results of piroxicam with these polymers.

The disappearance of the endothermic peak of lidocaine hydrochloride in the solid dispersion films containing HPC was obtained by some authors ${ }^{10}$. They explained this phenomenon on the basis that solid dispersion resulted in an amorphous form of the drug. Moreover, others ${ }^{11}$ showed that salicylic acid endothermic peak disappeared in both physical mixtures and coevaporate. They stated that this phenomenon could be correlated to an amorphous state of the drug present in the casting film due to incorporation of salicylic acid in Eudragit polymer.

However, the disappearance of the endothermic peak corresponds to the melting of piroxicam in the drug: polymer films may be due to its solubility in the melted polymer. This suggestion agrees with some investigators ${ }^{12}$ who showed the disappearance of the endothermic peak of hydrochlorothiazide in both physical mixture and solid dispersion with PEG 6000, which might indicate the solubility of the drug in the molten polymer during running the thermograms. Moreover, Khidr ${ }^{13}$ found the same behavior when he studied the solid dispersion of nifedipine with pluronic F: 127.

\section{X-Ray diffraction properties}

To get further evidence on the solid state change, X-ray diffraction pattern was carried out on untreated drug, medicated films formed of Eudragit RS100 and/or Eudragit RL100, Eudragit L100 and/or Eudragit S100 and their physical mixtures as well as the individual components. The presence of numerous distinct peaks in the x-ray diffraction spectrum of piroxicam indicates that piroxicam is present as a crystalline material with characteristic diffraction peaks appeared at diffraction angels of $2 \theta$ at $8.69 \mathrm{~A}^{\circ}, 14.57 \mathrm{~A}^{\circ}, 15.21 \mathrm{~A}^{\circ}, 15.83 \mathrm{~A}^{\circ}$, $17.75 \mathrm{~A}^{\circ}, 25.91 \mathrm{~A}^{\circ}, 26.82 \mathrm{~A}^{\circ}, 27.45 \mathrm{~A}^{\circ}$ and $34.37 \mathrm{~A}^{\circ}$ with relative intensities of $50,48,54$, $57,68,100,65,67$ and 22 respectively.

Eudragit RS100, Eudragit RL100, Eudragit L100 and Eudragit S100 polymers are amorphous in nature due to the absence of complete stereo regularity and presence of bulky side groups. Representative X-ray diffraction pattern for these polymers (Figs. 9,11 ) shows no sharp peaks. However, the physical mixture or the cast films of the same composition did not contain sharp peaks associated with drug molecules (Figs. 10,12). These diffraction patterns are identical to those of the pure polymer. The results strongly suggest the transformation of the drug from crystalline state to amorphous one in Eudragit polymer. These results are in agreement with other authors ${ }^{14}$ who found that drugs-PVP coprecipitates show disappearance of the $\mathrm{x}$-ray diffraction peaks of the drug crystals. 


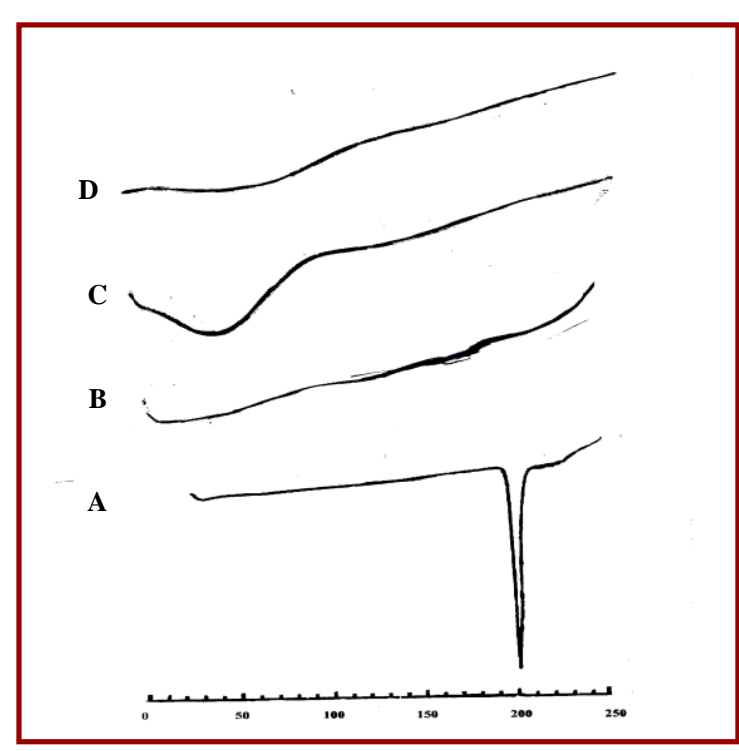

Temperature $\left({ }^{\circ} \mathrm{C}\right)$

Fig. 5: Differential scanning calorimetery (DSC) curves of (A) untreated piroxicam powder, (B) Eudragit RL100, (C) Eudragit RS100 and (D) piroxicam : Eudragit RL100 : Eudragit RS100 (2:25:25 w/w) physical mixture.

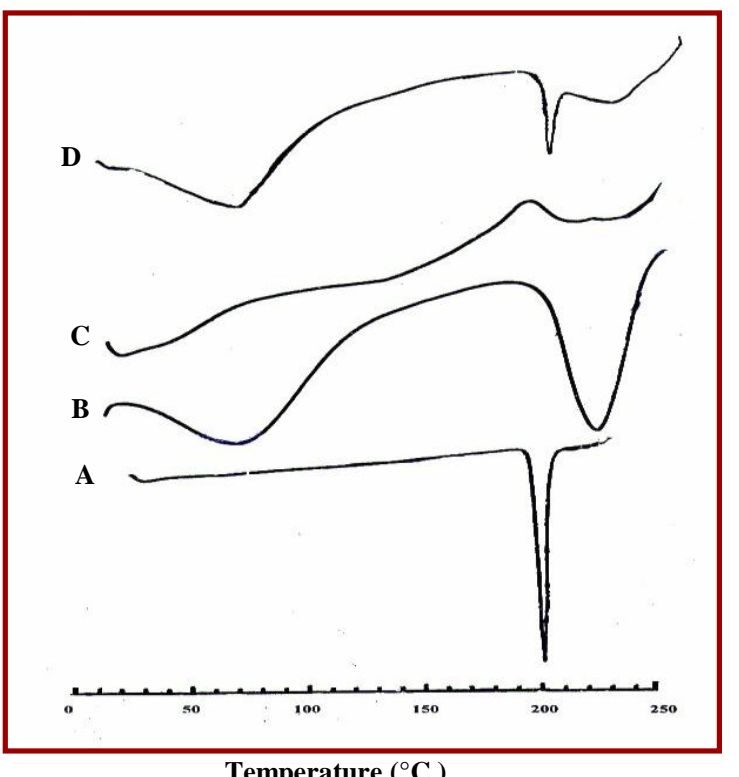

Fig. 7: Differential scanning calorimetery (DSC) curves of (A) untreated piroxicam powder, (B) Eudragit L100, (C) Eudragit S100 and (D) piroxicam : Eudragit L100 : Eudragit S100 (2:25:25 w/w) physical mixture.

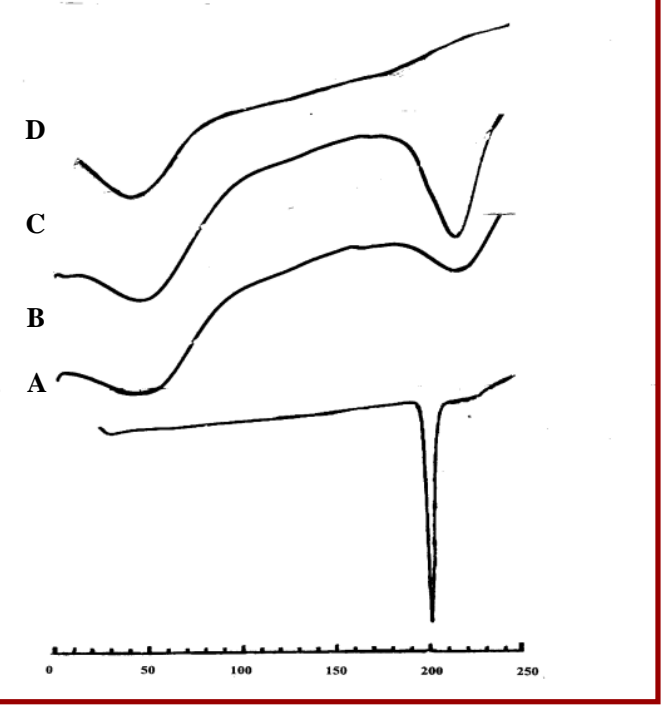

Temperature $\left({ }^{\circ} \mathrm{C}\right)$

Fig. 6: Differential scanning calorimetery (DSC) curves of (A) untreated piroxicam powder, (B) piroxicam : Eudragit RL100 (2:50 w/w) film, (C) piroxicam : Eudragit RS100 (2:50 $\mathrm{w} / \mathrm{w}$ ) film and (D) piroxicam : Eudragit RL100 : Eudragit RS100 (2:25:25 w/w) film.

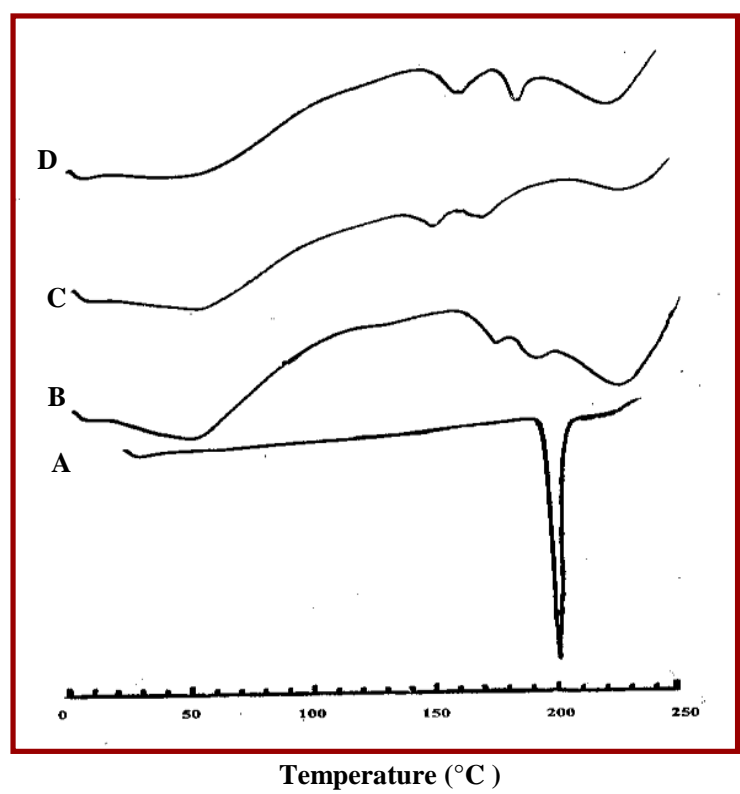

Fig. 8: Differential scanning calorimetery (DSC) curves of (A) untreated piroxicam powder, (B) piroxicam : Eudragit L100 $(2: 50 \mathrm{w} / \mathrm{w})$ film, (C) piroxicam : Eudragit S100 film $(2: 50 \mathrm{w} / \mathrm{w})$ and $(\mathrm{D})$ piroxicam : Eudragit L100 : Eudragit S100 (2:25:25: w/w) film. 


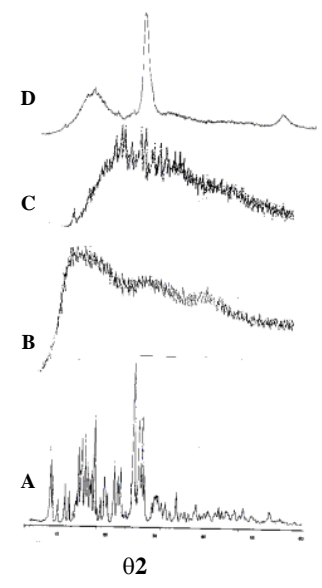

Fig. 9: X-ray diffraction pattern of (A) untreated piroxicam powder, (B) Eudragit RL100, (C) Eudragit RS100 and (D) piroxicam : Eudragit RL100 : Eudragit RS100 $(2: 25: 25 \mathrm{w} / \mathrm{w})$ physical mixture.

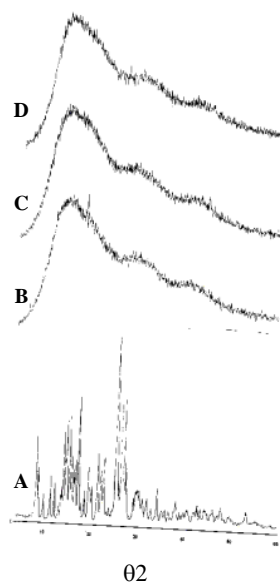

Fig. 10: X-ray diffraction pattern of (A) untreated piroxicam powder, (B) piroxicam : Eudragit RL100 (2:50 w/w) film, (C) piroxicam : Eudragit RS100 film (2:50 w/w) and (D) piroxicam : Eudragit RL100 : Eudragit RS100 (2:25:25: w/w) film.

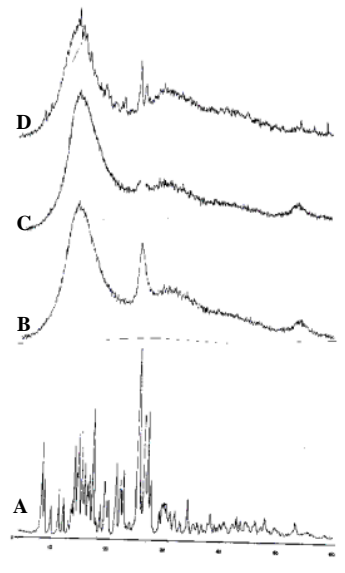

$\theta 2$

Fig. 11: X-ray diffraction pattern of (A) untreated piroxicam powder, (B) Eudragit L100, (C) Eudragit S100 and (D) piroxicam : Eudragit L100 : Eudragit S100 (2:25:25 w/w) physical mixture.

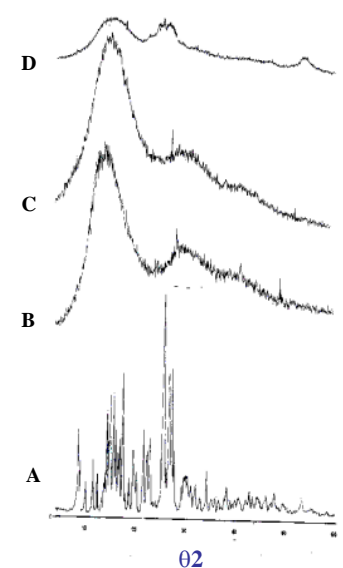

Fig. 12: $X$-ray diffraction pattern of (A) untreated piroxicam powder, (B) piroxicam : Eudragit L100 $(2: 50 \mathrm{w} / \mathrm{w})$ film, (C) piroxicam : Eudragit S100 film $(2: 50 \mathrm{w} / \mathrm{w})$ and (D) piroxicam : Eudragit L100 : Eudragit S100 (2:25:25: w/w) film.

\section{Evaluation of piroxicam release from Eudragit films}

Eudragit films of different polymeric ratios were prepared to investigate the effect of modification in polymeric ratios on drug release profile.

In-vitro release of piroxim from polymeric films was evaluated at different polymeric ratios. The ratios of Eudragit RS100 to Eudragit RL100 and Eudragit S100 to Eudragit L100 films were (10:0, 8:2, 6:4, 4:6, 2:8 and $0: 10)$. Each film contained $20 \mathrm{mg}$ of piroxicam. The obtained results are shown in Figures $(13,14)$.

Eudragit RS100 and Eudragit RL100 are neutral copolymers of ploy (ethylacrylate, methylmethacrylate and trimethylammonioethyl methacrylate chloride). Eudragit RS100 is less permeable than Eudragit RL100 due to its lower content of quaternary ammonium groups.

Eudragit S100 and Eudragit L100 are acrylic resin, copolymers, anionic in character, based on methacrylic acid and methacrylic acid methyl ester. Eudragit S100 is less permeable than Eudragit L100 due to its higher content of the ester groups. The ratio of the free carboxyl groups to the ester groups is about (1:1) in Eudragit L100 and a bout (1:2) in Eudragit S100. Figures $(13,14)$ show an acceleration of the release rate of the drug upon increasing the proportion of the more hydrophilic polymers (Eudragit RL100 or Eudragit L100) in the polymeric matrix. This could be explained through the high degree of hydration of the more hydrophilic polymer upon immersion the film in the buffer. Increased porosity, increased probabilities of hydrated channels formation and decreased tortuosity would accompany the greater hydration of Eudragit films containing increasing ratios of the more hydrophilic polymers (RL100 or Eudragit L100).

The presence of higher content of quaternary ammonium groups (in Eudragit RL100) or higher content of carboxyl groups (in Eudragit L100) resulted in an increase in the degree of film hydration and subsequently its effect on increasing the probabilities of hydrated channels formation. 


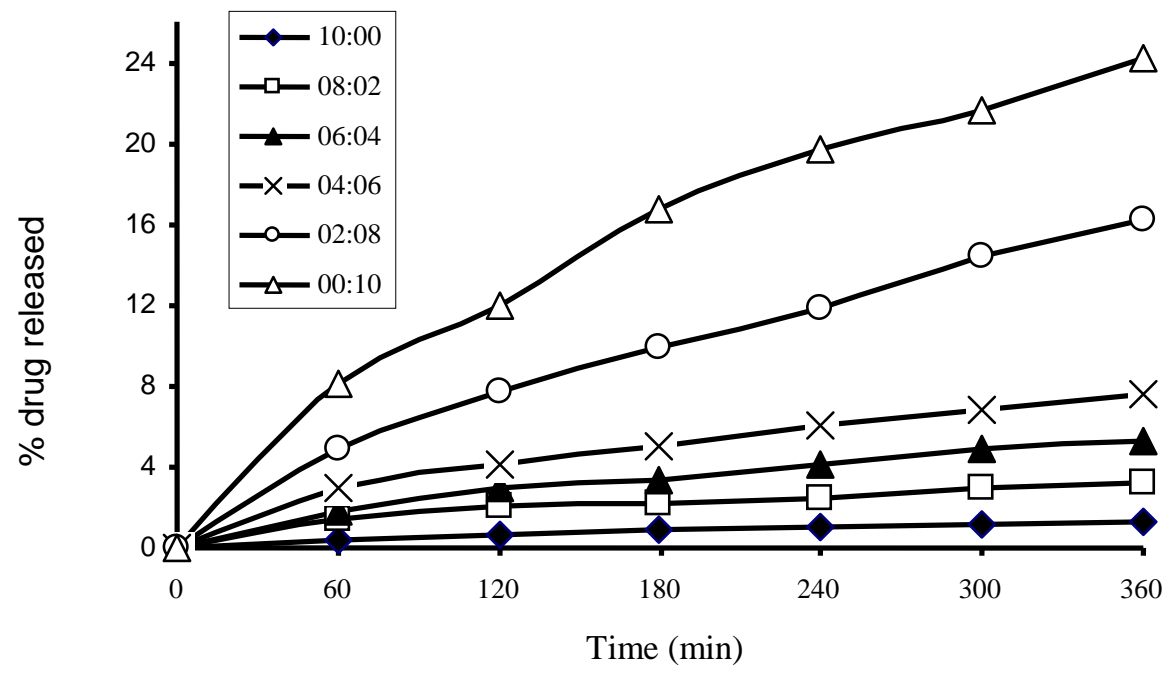

Fig. 13: Drug release profile from polymeric films each containing $20 \mathrm{mg}$ of piroxicam at different Eudragit RS100-Eudragit RL100 ratios.

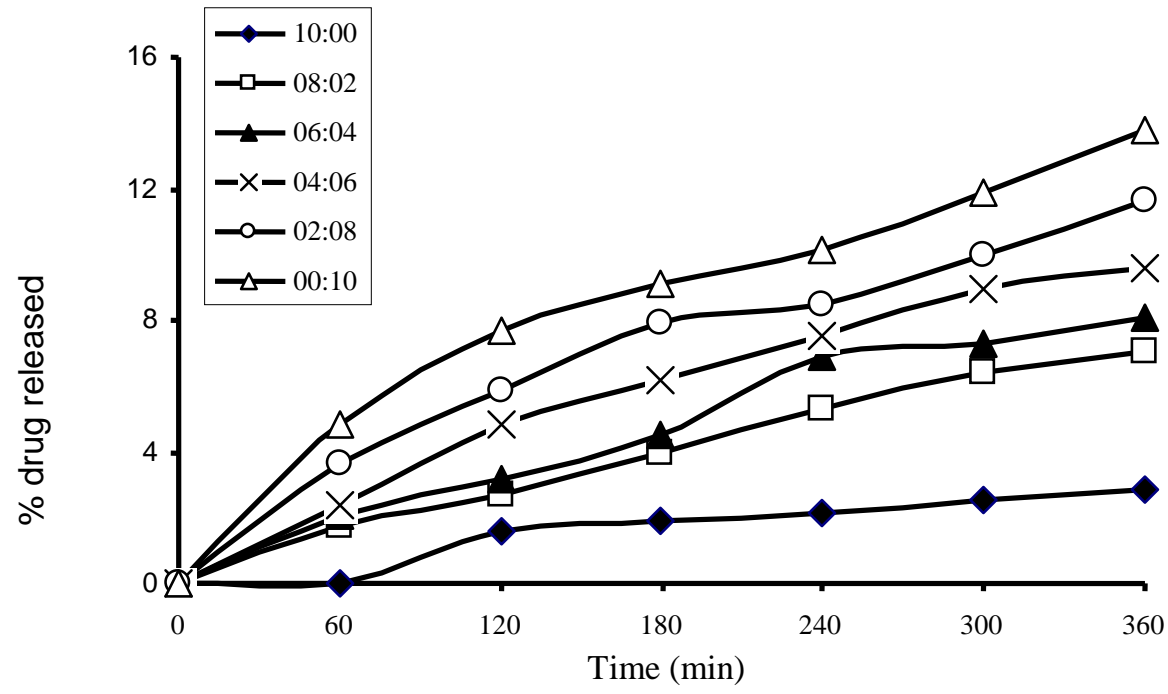

Fig. 14: Drug release profile from polymeric films containing $20 \mathrm{mg}$ of piroxicam at different Eudragit S100-Eudragit L100 ratios. 


\section{Conclusion}

As demonstrated above, Absence of changes in the location or width of characteristic infrared absorption bands of the drug in either physical mixture or cast films of Eudragit RL100 and/or Eudragit RS100 indicates that there is no molecular interaction between piroxicam and these two polymers. In contrast, presence of changes in the location and width of characteristic infrared absorption bands of the drug in both physical mixture and cast films of both Eudragit L100 and Eudragit S100 points to presence of a molecular interaction between piroxicam and both Eudragit L100 and Eudragit S100. The characteristic endothermic peak of piroxicam in its polymer almost disappeared or reduced in the intensity, shifted to lower temperatures or lost its sharpened distinct appearance. These observations indicate the presence of piroxicam in an amorphous form in these physical mixtures or cast films. X-ray diffraction studies showed that piroxicam crystalline peaks were not observed in either its cast films or in its physical mixture. This was attributed to the conversion of the drug from the crystalline state to the amorphous one. In-vitro drug release study showed an acceleration of the release rate of the drug upon increasing the proportion of the more hydrophilic polymers (Eudragit RL100 or Eudragit L100) and decreasing the proportion of the less hydrophilic ones (Eudragit RS100 or Eudragit $\mathrm{S} 100)$ in the polymeric matrix.

\section{REFERENCES}

1- M. Mihalic, H. Hofman, J. Kuftince, B. Krile, V. Caplar, P. Kajfez and N. Blazevic, Piroxicam, Anal. Prof. Drug Subst., 15, 509 (1986).

2- C. M. Williamson, Curr. Med. Res. Opin., 8, 622 (1983).

3- M. Mihalic, H. Hofman, F. Kajfez, J. Kuftinec, N. Blazevic and M. Zinic, Acta Pharm. Jugoslav., 32, 13(1982).

4- F. Vrecer, S. Srcic and J. Smid-Korbar, Int. J. Pharm., 68, 35 (1991).

5- S.H. Auda, "Preparation and Evaluation of Some Medicated Polymeric Films Containing Piroxicam", Master Thesis, Faculty of Pharmacy, Al-Azhar University, Assiut, Egypt (2004).

6- S. Y. Lin, R. I. Perng and C. L. Cheng, Eur. J. Pharm. Biopharm., 42, 62 (1996).

7- K. Adibkia, M. R. S. Shadbad, A. Nokhodchi, A. Javadzedeh, M. BarzegarJalali, J. Barar, G. Mohammadi and Y. Omidi, J. Drug Targ., 15, 407 (2007).

8- M. Maghsoodi and F. Sadeghpoor, Drug Develop. Ind. Pharm., 36, 1 (2010).

9- V. Tantishaiyakul, N. Kaewnopparat and S. Ingkatawornwong, Int. J. Pharm., 143, 59 (1996).

10- Y. Kohda, H. Kobayashi, Y. Baba, H. Yuasa, T. Ozeki, Y. Kanaya and E. Sagara, ibid., 158, 147 (1997).

11- A. Ismail, M. Abd El-Mohsen and H. A. El-Ghamry, Zagazig J. of Pharm. Sci., 7, 111 (1998).

12- A.P. Simonelli, M. M. Meshali, A. H. Abd El-Gawad, H. M. Abdel-Aleem and K. E. Gabr, Drug Dev. Ind. Pharm., 20, 2741 (1994).

13- S. H. Khidr, Bull. Pharm. Sci., Assiut University, 17, 81 (1994).

14- N. M. Najib, M. A. El-Hinnawi and M. S. Suleiman, Int. J. Pharm., 45, 139 (1988). 